\title{
Acceptability of HIV Testing and Counseling Services among Persons Visiting a Funeral Home in a Regional Referral Hospital in Western Kenya, 2014-2015
}

\author{
Barbara Burmen ${ }^{1} \&$ Kennedy Kipkoech Mutai ${ }^{1}$ \\ ${ }^{1}$ Kenya Medical Research Institute-Center for Global Health Research, Kisumu, Kenya. \\ Correspondence: Barbara Burmen, HIV Implementation Science and Services, Kenya Medical Research \\ Institute-Center for Global Health Research, Kisumu, Kenya.
}

Received: March 16, 2016

doi:10.11114/ijsss.v4i6.1557
Accepted: April 1, 2016

Available online: April 15, 2016

\begin{abstract}
Funeral homes in health facilities are accessed by persons who may not visit other parts of the hospital to access HTC services. Between November 2014 and February 2015, all persons visiting the Jaramogi Oginga Odinga Teaching and Referral Hospital funeral home were offered HTC and grief counseling services and interviewed to determine the acceptability of HTC services at this location. This was done as they waited for various services. 'Acceptability' was defined as the proportion of those who felt people should receive HTC services at the funeral home. Qualitative data was manually coded and thematically analyzed. Of 609 persons interviewed, majority were aged 25-34 years (33\%), female $(54 \%)$, married $(68 \%)$, of primary level education $(39 \%)$, self-employed $(49 \%)$ and were not related to the deceased (53\%). Majority had come to collect/bring the body of the deceased (63\%) and had undergone prior testing (91\%). A minority (2\%) who found HTC services unacceptable were aged 18-24 years (42\%), single (50\%), of tertiary level education (58\%), came to collect/bring the bodies of their deceased (83\%), had ever been tested (92\%) and were self-employed (33\%) or unemployed (33\%). Respondents stated that this was because, “....the bereaved not in the right frame of mind" (76\%) and "...the HTC service-providers were very conspicuous" (26\%). Acceptability did not differ by age-group, gender or relationship to the deceased. Of the $569(93 \%)$ who were tested, $42(7 \%)$ were first-time testers; HIV prevalence was $3 \%$ and 5\% respectively. Funeral homes provide acceptable avenues for increasing access to knowledge of HIV status which could have a substantial impact on the HIV epidemic.
\end{abstract}

Keywords: Acceptability, HIV testing, Funeral homes

\section{Introduction}

At the end of 2013, there were 35 million HIV-infected persons globally; of whom $71 \%$ of them were residing in sub-Saharan Africa (World Health Organization,2016). According to the Kenya Demographic and Health Survey of 2012, the national HIV prevalence was 5.6\%. In the same survey, the former Nyanza province of Kenya had a HIV prevalence of $14.1 \%$ (National AIDS and STI Control Program,2014).

HIV testing and counseling (HTC) forms a key entry point for linkage to HIV prevention, care and treatment services (World Health Organization,2013). With universal access to knowledge of HIV status, HIV programs can effectively mitigate the effects of HIV, by reducing HIV transmission rates from HIV positive persons to HIV negative persons through ART provision, and improving the quality of life of HIV-infected persons (World Health Organization,2003). Majority of HIV prevention programs have focused on behavior change because HIV transmission is predominantly heterosexual; however, individuals should be knowledgeable of their correct HIV status for the appropriate and informed action (Ziraba AK et al.,2011). Increasing knowledge of HIV status could have a substantial impact on the HIV epidemic; HIV transmission rates reduced from 6.9 per 100 persons years to 2.0 per 100 person years in the US among persons who knew they were HIV positive (Cherutich P, Bunnell R, \& Mermin J,2013).

However, in 2012, 63\% of HIV positive persons who participated in a nationwide survey in Kenya did not know their status (National AIDS and STI Control Program,2014). There is therefore, a need to increase access to HIV counseling and testing services(National AIDS and STI Control Program,2010). 
The World Health Organization (WHO) recommended the scale up of HIV testing in 2003 in both routine clinical care and in a broader range of public health settings e.g. the TB clinic, STI clinic and Voluntary Counseling and Testing (VCT) sites, so that clients can access options that suit their interests and convenience (World Health Organization,2003). The WHO and Joint United Nations Programme on HIV/AIDS (UNAIDS) then endorsed the concept of 'universal access to knowledge of HIV status by the year 2010' (World Health Organization,2013). Kenya committed to the UNAIDS goal of 'universal access' to knowledge of HIV status by providing HTC services at different settings e.g. health facilities, workplaces, outreaches and homes (National AIDS and STI Control Program,2010). Non-hospital based HIV testing locations are useful in reaching majority of the population who have limited contact with health care providers (Suthar AB et al.,2013). Currently, Provider Initiated Testing and Counseling (PITC) programs in Kenya offer HTC to all hospital patients and visitors who visit public health facilities in Kenya. This differs from VCT, where the testing is client-initiated (National AIDS and STI Control Program,2010).

Various counseling and testing models need to be evaluated in order to determine their effectiveness, cost and social impacts (World Health Organization,2003). This should be based on the nature of the epidemic ( generalized epidemics would require PITC in all health care contacts), the cost effectiveness of the site selected in reaching as many people as possible, equity of access for underserved populations and the available resources (site selection should make maximum use of existing resources) (World Health Organization,2012). Jaramogi Oginga Odinga Teaching and Referral Hospital (JOOTRH) is the regional referral hospital of the formerly Nyanza Province of Kenya (Ministry of Health,2011). HTC services at JOOTRH which conform to the national guidelines for HTC , are offered at all service delivery points, including the funeral home by a team of lay counselors who participate in quarterly proficiency testing and bi-annual observed practice (National AIDS and STI Control Program,2010). However, there is minimal testing at the funeral home which receives between 100- 400 visitors daily, including religious leaders, casket-transporters, bereaved relatives and friends yet this is an accessible population for HTC services (Audo C., Provider Initiated Testing Coordinator, JOOTRH, Personal Communication, $13^{\text {th }}$ January, 2013).

With the high HIV burden in Nyanza province and such a large number of persons visiting the funeral home on a daily basis, extension of PITC services to the funeral home would be a cost effective means of increasing access to HTC services. Although there is the potential possibility of psychological harm in the event a bereaved person is made to experience two major life changing events in the span of hours to weeks i.e. emotional stress due to acute grief and the potentially distressing information concerning a positive HIV diagnosis, the potential benefits of HIV testing still surpass this (Kubler-Ross E,1969; National AIDS and STI Control Program,2010). Furthermore, the death of a sexual partner or child has been associated with an elevation of perceived risk of infection and therefore a decision to undergo HIV testing in a systematic review of qualitative studies on enabling and deterring factors to HIV testing in Sub-Saharan Africa (Musheke M et al.,2013).

The provision of HTC in funeral homes is unprecedented. The level of psychological burden borne by bereaved persons differs depending on the relationship with the deceased and individual personalities; we therefore expect varying levels of acceptability of HIV testing (Kentish-Barnes N, Chevret S, \& Azoulay E,2016). We have examined the acceptability and utilization of HTC services among persons visiting a funeral home in a high HIV burden region.

\section{Methods}

\subsection{Study design and setting}

Semi-structured interviews were conducted at the JOOTRH funeral home in Kisumu County of the former Nyanza province of Kenya in order to determine the acceptability of PITC services at this location. The hospital is a regional referral facility in Nyanza and accessible to Western Province and part of Rift Valley Province (Ministry of Health,2011). On a monthly basis the hospital's funeral home handles about 120 bodies of deceased people and is visited by approximately 100 persons daily. Generally, most persons visit the funeral homes on Thursdays and Fridays to collect the bodies of their deceased relatives in preparation for interment over the weekend and on other weekdays to view or bring the bodies of their deceased relatives (Audo, C, personal communication, 12th June 2014).

\subsection{Study population}

This included all persons utilizing the funeral home services between November 2014 and February 2015 aged 18 years or older who were not in an obvious agitated state and provided written informed consented to participate in the interviews.

\subsection{Study procedures}

HIV testing and counselling providers certified by the National AIDS and STI Control Program (NASCOP), in Kenya were equipped with counselling skills on loss and grief prior to implementation of client interviews. They then approached persons visiting the funeral home, assessed their psychological state and provided initial grief counseling as 
necessary. Persons not in obvious agitated emotional state were then invited for HIV testing and interview with an option to refuse or defer either HIV testing or interview or both. This was done as they waited to view or preserve or collect the bodies of their deceased and complete the necessary administrative procedures. All HIV infected person were offered referral letters to HIV clinics of their choice and phone calls made within a month to confirm enrolment at these clinics. Phone calls were not made to confirm receipt of HIV preventive services for persons who tested HIV negative.

\subsection{Data management}

\subsubsection{Data collection}

A questionnaire (with open and closed ended questions) and standard HTC register with were used to collect data on participant demographic characteristics, HIV testing history and their views on the availability of HTC services at the funeral home. Both quantitative and qualitative data (free-text answers) were collected using the same questionnaire which was administered by trained PITC counselors prior to HIV testing. A daily tally was conducted to estimate the number of persons visiting the morgue on each day of the week. The whole process of interview and testing took approximately 25-30 minutes to complete.

\subsubsection{Data analysis}

Data was uploaded into MS Access databases and exported into SAS 9.2 Software for analysis(SAS Institute Inc,2012) . The characteristics of study participants were described by computing proportions for categorical variables. 'Acceptability' was defined as the proportion of those who felt people should receive HTC services at the funeral home. Qualitative data was manually coded and thematically analyzed.

\subsection{Ethical considerations}

This study was approved by the Kenya Medical Research Institute Ethics Review Committee (KEMRI SSC. No. 2644).

\section{Results}

Table 1. Acceptability of HIV testing services at the Jaramogi Oginga Odinga Teaching and Referral Hospital funeral home, 2014-2015

\begin{tabular}{|c|c|c|c|}
\hline Characteristics & $\begin{array}{c}\text { Total } \\
609\end{array}$ & $\begin{array}{c}\text { Find HTC services at the } \\
\text { funeral home acceptable } \\
\mathbf{N = 5 9 7 ( 9 8 \% )} \\
\mathbf{n}(\%)\end{array}$ & $\begin{array}{c}\text { Find HTC services at the funeral } \\
\text { home unacceptable } \\
\mathbf{N = 1 2 ( 2 \% )} \\
\mathbf{n}(\mathbf{\%})\end{array}$ \\
\hline \multicolumn{4}{|l|}{ Age-group } \\
\hline $18-24$ years & $116(19)$ & $111(19)$ & $5(42)$ \\
\hline $25-34$ years & $201(33)$ & $198(33)$ & $3(25)$ \\
\hline $35-44$ years & $120(20)$ & $117(20)$ & $3(25)$ \\
\hline 45 +years & $172(28)$ & $171(28)$ & $1(8)$ \\
\hline \multicolumn{4}{|l|}{ Sex } \\
\hline Male & 277 (46) & $271(45)$ & $6(50)$ \\
\hline Female & $332(54)$ & $326(55)$ & $6(50)$ \\
\hline \multicolumn{4}{|l|}{ Marital Status } \\
\hline Single & $133(22)$ & $127(21)$ & $6(50)$ \\
\hline Married & $411(68)$ & $406(68)$ & $5(42)$ \\
\hline Widowed & $50(8)$ & $49(8)$ & $1(8)$ \\
\hline Divorced/Separated & $15(2)$ & $15(3)$ & $0(0)$ \\
\hline \multicolumn{4}{|l|}{ Educational level } \\
\hline None & $34(6)$ & $34(6)$ & $0(0)$ \\
\hline Primary & $240(39)$ & $239(40)$ & $1(8)$ \\
\hline Secondary & $188(31)$ & $184(31)$ & $4(33)$ \\
\hline Tertiary & $147(24)$ & $140(23)$ & $7(58)$ \\
\hline \multicolumn{4}{|l|}{ Occupation } \\
\hline Casual laborer & $59(10)$ & $58(10)$ & $1(8)$ \\
\hline None & $113(19)$ & $109(18)$ & $4(33)$ \\
\hline Self employed & $298(49)$ & $294(49)$ & $4(33)$ \\
\hline Formal employment & $86(14)$ & $83(14)$ & $3(25)$ \\
\hline Driver & $40(7)$ & $40(7)$ & $0(0)$ \\
\hline
\end{tabular}




\begin{tabular}{|c|c|c|c|}
\hline Religious leaders & $13(2)$ & $13(2)$ & $0(0)$ \\
\hline \multicolumn{4}{|l|}{ Day of the week* } \\
\hline Monday & $102(17)$ & $100(17)$ & $2(17)$ \\
\hline Tuesday & $134(22)$ & $132(22)$ & $2(17)$ \\
\hline Wednesday & $101(17)$ & 99 (17) & $2(17)$ \\
\hline Thursday \& Friday & $272(44)$ & $266(44)$ & $6(50)$ \\
\hline \multicolumn{4}{|l|}{ What brought you here* } \\
\hline Collect/Bring body & $385(63)$ & $375(63)$ & $10(83)$ \\
\hline View Body & $130(21)$ & $128(16)$ & $2(17)$ \\
\hline Other reasons & $94(15)$ & $94(21)$ & $0(0)$ \\
\hline \multicolumn{4}{|c|}{ Relationship to deceased $*$} \\
\hline Related & $298(47)$ & $283(47)$ & $6(50)$ \\
\hline Not related & $320(53)$ & $314(52)$ & $6(50)$ \\
\hline \multicolumn{4}{|c|}{ History of prior HIV testing } \\
\hline Yes & $552(91)$ & $541(91)$ & $11(92)$ \\
\hline No & $57(9)$ & $56(9)$ & $1(8)$ \\
\hline
\end{tabular}

3.1 Participant characteristics

On average, a total of 779 persons visited the funeral home each week and over $85 \%$ of them visited on Thursdays and Fridays.

A total 609 persons who visited the funeral home during the study period consented to being interviewed; majority were aged 25-34 years $(33 \%)$, female (54\%), married (68\%), of primary level education (39\%), were self-employed (49\%) and were not related to the deceased $(53 \%)$.

Majority visited the funeral home on Thursdays and Fridays (44\%), to collect/bring the body of the deceased (63\%) and had undergone prior testing $(91 \%)$ (Table 1)

\subsection{Awareness of availability of HTC services at the funeral home}

Of the 609 , majority $(530,87 \%)$ were not aware HTC services were offered at the funeral home and the $79(13 \%)$ that knew HTC services were available at this location had learnt this from; the banners hung around the hospital and funeral home $(62 \%)$, the hospital $(8 \%)$, another person $(14 \%)$, a prior visit to the morgue $(8 \%)$ and from seeing the counselors and the tents $(9 \%)$.

\subsection{Acceptability of HTC services at the funeral home}

Majority $(98 \%$; 597) found HTC at the funeral home acceptable. This is was because; a lot of people gathered at the morgue $(39 \%)$, it provided a good opportunity to know one's HIV status $(25 \%)$, of preference for non-hospital HIV-testing sites $(15 \%)$, it put to good use the waiting time spent at the funeral home (9\%), the death could prompt his relatives or acquaintances to undergo HTC (6\%), it ensured anonymity of persons tested (3\%) and for undocumented reasons $(3 \%)$.

Among those who found HTC services at the morgue unacceptable (2\%), majority were persons who were aged $18-24$ years $(42 \%)$, single $(50 \%)$, of tertiary level education $(58 \%)$, persons who visited the funeral home on Thursdays and Fridays $(50 \%)$, persons who came to collect or bring the bodies of their deceased $(83 \%)$, person who had received prior testing $(92 \%)$ and those who were self-employed $(33 \%)$ or unemployed $(33 \%)$. Acceptability did not differ by gender or relationship to the deceased. Those who found HTC services unacceptable cited that this was because "...the bereaved were not in the right frame of mind..." (76\%) and “...the HTC service-providers were very conspicuous...” (26\%).

\subsection{Suggestions to improve HTC services at the JOOTRH funeral home}

To improve HTC services at the site, 597 persons proposed that; HIV testing be done in private (68\%), the HIV-testing points be increased (17\%), the availability of HIV-testing services at the funeral home be publicized (6\%), and undocumented reasons $(9 \%)$.

\subsection{HIV prevalence}

Among the participants, $595(98 \%)$ underwent HTC of whom $43(7 \%)$ had never undergone prior testing (first time testers); HIV prevalence was 3\% among all tested and 5\% among first time testers. Those who declined testing did so for undocumented reasons (50\%), had undergone recent testing (29\%), were enrolled in HIV clinics (14\%) and were not emotionally prepared to undergo HIV testing (7\%). Among the 12 who found HIV testing at the funeral home 
unacceptable, 11 (92\%) still underwent HIV testing.

\subsection{Referrals to HIV Health services}

Among the 17 who were HIV positive, 14 (82\%) accepted to be referred to HIV clinics of their choice; two of the three who declined referral preferred to disclose their positive HIV status to their spouses prior to referral while the other wanted to confirm their HIV positive results elsewhere. Of the 14 who were referred, ten were contacted on phone to confirm linkage to HIV clinics; the other four HIV-infected persons could not be reached on phone. Of the 10 called, 4 (40\%) were enrolled at HIV clinics; the remainder, declined referral (50\%), intended to go later (33\%) and offered no response $(17 \%)$.

Among the 592 who were HIV negative, 471 answered questions on referrals to HIV prevention services; 458 (98\%) wished to be referred to HIV prevention services. Those who did not wish to be referred said they, would not have the time to go $(62 \%)$, were not interested (15\%), were not married (7\%) or were domiciled far from health service $(7 \%)$ or for unknown reasons (7\%). Those who wished to be referred said they wished to be referred for partner testing (53\%), HIV educational programs (34\%), cervical cancer screening (14\%), Family planning services (12\%), condom collection (9\%), VMMC (4\%), STI treatment (4\%), nutritional counseling (3\%), and other services i.e. blood donation, Tuberculosis screening and medical services (1\%). Condoms were also offered to all persons interviewed.

\section{Discussion}

We set out to determine the acceptability of HIV counseling and testing services among persons visiting a funeral home in a regional referral hospital in a high HIV burden region. HIV testing among visitors at the JOOTRH funeral home is unprecedented in Kenya. Our evaluation revealed that HIV counseling and testing services were acceptable within a majority (99\%) this population. Similar rates have been observed within other sections of the hospital served by the funeral home from unpublished HIV program data (95\%), and among pregnant women in Malawi who attended ANC clinics between 2002 and 2003 (99\%), and during door to door testing within a Siaya County, a rural setting within the former Nyanza(85\%) in 2008 (Manzi M et al.,2005; Medley A et al.,2012). Acceptability rates among ANC women in Africa are generally higher than those seen in previous years; 69\% (35\%-95\%) (Cartoux M et al.,1998). This could be attributed to increasing availability of ART and destigmatization of HIV infection (Treves-Kagan S et al.,2016).

The high acceptability rates could also be due to the opt-out approaches used in our evaluation. Opt out approaches are recommended by the Ministry of health in Kenya to increase the coverage of HIV testing. This approach could be justified through the doctrines of "libertarian paternalism" and "consequentialism" which describe that it is possible to encourage people to make welfare-maximizing choices without being coercive (April MD,2010; Hanssens C,2007; Metz T,2005). In Edinburgh, acceptability increased 6 fold when pregnant women were offered HIV testing services compared to when HIV testing was done enly upon the request of the pregnant woman (Simpson WM et al.,1998). This is supported by the fact that among women who were not tested in pregnancy in Zimbabwe, 79\% would have accepted HIV testing if it had been offered during pregnancy (Perez F, Zvandaziva C, Engelsmann B, \& François D,2006).

High acceptability rates have been associated with presenting counseling and testing as routine rather than optional in the United States (Irwin KL, Valdiserri RO, \& Holmberg S,1996;Abudrahman S, Seyoum B, Oljira O, \& Weldegebreal F,2015). Provision of opt-out HIV testing has been shown to be useful in identifying HIV seropositive persons who are unaware of their HIV status especially in high HIV prevalence areas (Bassett IV et al.,2007; Walensky RP, Losina E, Steger-Craven KA, \& Freedberg KA,2002). It aides in identifying a higher proportion of HIV positive persons early in the natural history of the disease (White DAE, Scribner AN, Schulden JD, Branson BM, \& Heffelfinger JD,2009). This is a strategy that has been advocated for by the Kenyan Ministry of Health to promote universal access to knowledge of HIV status (National AIDS and STI Control Program,2010). In an urban slum in Nairobi, only 53\% of the population had undergone prior testing of whom close to half were tested during PITC. PITC therefore aided in increasing the overall testing rates of this population (Ziraba AK et al.,2011).

In the literature, the convenient timing, confidentiality, place and location of testing and credibility provided by door to door HIV testing were cited as reasons as to why door to door testing was preferred over Voluntary Counselling and testing (Angottia N et al.,2009; Irwin KL et al.,1996; Jerene D, Endale A, \& Lindtjørn B,2007; Medley A et al.,2012). The core principles of HIV testing, counseling, confidentiality, consent, correct results and connection to HIV prevention and treatment services are just as important in community-based HTC approaches as in non-hospital based HTC approaches (Suthar AB et al.,2013). Our evaluation revealed that only a minority of persons tested questioned the credibility of their HIV test results. The use of HTC services in both health facilities and mobile clinics has also been linked to their availability and accessibility (Meehan SA et al.,2015 ). By bringing HTC services closer to people, non-hospital based HTC services reduce the costs of travelling and waiting times (Musheke M et al.,2013). Low uptake of HTC services therefore require innovative strategies to prevent missed opportunities (Perez F et al.,2006). HTC programs should enhance counseling skills of their staff, increase counseling test points and address HIV-related stigma 
to improve HTC acceptability rates (Kilewo C et al.,2001; Perez F et al.,2006). Similar suggestions were cited by participants in our evaluation.

The yield of HIV testing in our evaluation was slightly lower than that observed in other parts of the hospital as evidenced by unpublished HIV program data (HIV prevalence 6\%). Hospital based approaches are more likely to test sicker persons. Additionally, HIV prevalence rates observed in community testing approaches are more likely to be representative of the general population (Suthar AB et al.,2013). In an attempt to target an AIDS-free generation, evidence-based interventions ought to be targeted to where populations at greatest risk of HIV or with highest HIV incidence reside (Department of State United States of America,2014). Recently, the Kenya AIDS strategic framework of 2014/2015-2018/2019 recommended granulating the HIV epidemic to target prevention interventions for geographical regions depending on their incidence of HIV and priority populations who disproportionately contribute to the high number of new HIV infections (National AIDS and STI Control Program,2013).

Nevertheless, HTC at this location aided in identifying a substantial proportion of persons who had never been tested before (first-time testers) compared to unpublished HIV program data from the rest of the hospital who had only $29 \%$ of persons tested as first-time testers of whom $4.9 \%$ were HIV positive (Audo, C, personal communication, 12th June 2014). Community-based HTC approaches, defined as, HIV testing outside the confines of a health facility and includes location that are frequently visited by the general population, are more useful in identifying more first-time testers (Suthar AB et al.,2013). Furthermore, , all HIV negative persons were offered condoms and a referral to HIV preventive and other health services emphasizing the importance of HTC in reducing HIV transmission and indirectly improving the use of other health services.

Although associations between participants characteristics and acceptability of HIV testing have been observed in the literature, we could not ascertain this due to only a minority of persons interviewed finding HIV counseling and testing at the funeral home unacceptable. Additionally, only persons in non-agitated state were tested, for ethical reasons, this may have biased the acceptability results (by increasing the acceptability), and possibly the HIV results (maybe more agitated were unaware the deceased had HIV and died from this, making them more 'susceptible' to infection). We were also unable to confirm linkage to HIV preventive services for HIV negative persons which may have provided an estimate of the preventive benefit of HTC programs.

In conclusion, funeral homes, which are visited by several persons, provide an acceptable avenue for HIV testing programs to increase populations' access to knowledge of HIV status. This is because non hospital settings have been shown to be successful in diagnosing previously undiagnosed persons who may or may have not has a test until later in the natural history of the course of HIV infection (Thornton AC et al.,2012; Suthar AB et al.,2013). Although opt-out approaches to HIV testing may seem resource-intensive, screening programs in high HIV prevalence areas identify HIV positive persons at a lower cost per diagnosis (Pizzo E, Rayment M, Thornton AC, \& Sullivan AK,2012). Opt-out approaches would also decrease the stigma associated with a HIV test since a HIV test is offered to all persons (Manongi R, Mahande M, \& Njau B,2014). Given the reported persistence of stigma, HIV programs should continuously formulate AIDS communication and educational messages that address stigma which is a main hindrance to HIV testing (Musheke M et al.,2013; Tshuma NT et al.,2015). HIV programs should contextualize HTC programs to suit their target populations while adhering to the ethical principles of consent, confidentiality and counseling to safeguard the interest of their clients (Abudrahman S et al.,2015; Manongi R et al.,2014). This is because the salient policy about HIV testing scale up is not whether it should be done or not, but how it should be done (Obermeyer CM et al.,2013). This will ensure HIV programs explore the use of other settings for HTC which will not only improve access to knowledge of HIV status but also and provide the highest yield in identifying persons with HIV infection and attain HIV prevention and treatment goals.

\section{Acknowledgements}

We wish to acknowledge the contribution of the healthcare workers and all persons visiting the JOOTRH funeral home. We also wish to acknowledge the work of the HTC team and the entire data team. We also thank the Kenya Ministry of Health, including the National AIDS and STI Control Program, and the KEMRI Director for their collaboration in this study.

\section{References}

Abudrahman, S, Seyoum B, Oljira, O., \& Weldegebreal, F. (2015). Factors affecting acceptance of provider-initiated HIV testing and counselling services amogn outpatient clinics in selected health facilties in Harar Town, Eastern Ethiopia. HIV/AIDS -Research and Palliative Care, 7, 157-165. http://dx.doi.org/10.2147/HIV.S81649

Angottia, N., Bulab, A, Gaydoshc L, Kimchid, E. Z., Thorntone, R. L., \& Yeatmanf, S. E. (2009). Increasing the acceptability of HIV counseling and testing with three C's: Convenience, confidentiality and credibility. Social 
Science \& Medicine, 68(12), 2263-2270. doi:http://dx.doi.org/10.1016/j.socscimed.2009.02.041

April, M. D. (2010). Rethinking HIV exceptionalism: the ethics of opt-out HIV testing in Sub-Saharan Africa. Bulletin of the World Health Organization, 88, 703-708. http://dx.doi.org/10.2471/BLT.09.073049

Bassett, IV, Giddy, J., Nkera, J., Wang, B., Losina, E., Lu, Z. (2007). Routine Voluntary HIV Testing in Durban, South Africa: The Experience From an Outpatient Department. Journal of Acquired Immune Deficiency Syndrome, 1(2), 181-186. http://dx.doi.org/10.1097/QAI.0b13e31814277c8

Cartoux, M., Meda, N., Van de Perre, P., Newell, ML., de Vincenzi, I., \& Dabis, F. (1998). Acceptability of voluntary HIV testing by pregnant women in developing countries: an international survey. AIDS, 12(18), 2489-2493.

Cherutich, P., Bunnell, R., \& Mermin, J. (2013). HIV testing: current practice and future directions. Current HIV/AIDS Reports, 10(2), 134-141. http://dx.doi.org/10.1007/s11904-013-0158-8

Department of State United States of America. (2014). PEPFAR 3.0 Controlling the Epidemic: Delivering on the promise of an AIDS-free generation. Retrieved from http://www.pepfar.gov/documents/organization/234744.pdf

Hanssens, C. (2007). Legal and ethical implications of Opt-Out HIV testing. Clinical Infectious Diseases, 45, S232-239. http://dx.doi.org/10.1086/522543

Irwin, K. L., Valdiserri, R. O., \& Holmberg, S. (1996). The acceptability of voluntary HIV antibody testing in the United States: A decade of lessons learned. AIDS, 10(14), 1707-1717.

Jerene, D., Endale, A., \& Lindtjørn, B. (2007). Acceptability of HIV counselling and testing among tuberculosis patients in south Ethiopia. BMC International Health and Human Rights, 7, 4. http://dx.doi.org/10.1186/1472-698X-7-4

Kentish-Barnes, N., Chevret, S., \& Azoulay, E. (2016). Impact of the condolence letter on the experience of bereaved families after a death in intensive care: study protocol for a randomized controlled trial. Trials, 17(1), 102. http://dx.doi.org/10.1186/s13063-016-1212-9

Kilewo, C., Massawe, A., Lyamuya, E., Semali, I., Kalokola, F., \& Urassa, E. (2001). HIV Counseling and Testing of Pregnant Women in Sub-Saharan Africa: Experiences From a Study on Prevention of Mother-to-Child HIV-1 Transmission in Dar Es Salaam, Tanzania. Journal of Acquired Immune Deficiency Syndromes, 28(5), $458-462$.

Kubler-Ross E. (1969). On death and dying. New York: The Macmillan Company.

Manongi, R., Mahande, M., \& Njau, B. (2014). Knowledge, attitudes and acceptability to provider-initiated HIV testing and counselling: patients' perspectives in Moshi and Rombo Districts, Tanzania. Tanzania Journal of Health Research, 16. http://dx.doi.org/10.4314/thrb.v16i4.6

Manzi, M., Zachariah, R., Teck, R., Buhendwa, L., Kazima, J., \& Bakali, E. (2005). High acceptability of voluntary counselling and HIV-testing but unacceptable loss to follow up in a prevention of mother-to-child HIV transmission programme in rural Malawi: scaling-up requires a different way of acting. Tropical Medicine \& International Health, 10(12), 1242-1250. http://dx.doi.org/10.1111/j.1365-3156.2005.01526.x

Medley, A., Ackers, M., Amolloh, M., Owuor, P., Muttai, H., \& Audi, B. (2012). Early Uptake of HIV Clinical Care After Testing HIV-Positive During Home-Based Testing and Counseling in Western Kenya. AIDS and Behavior, 17(1), 224-234. http://dx.doi.org/10.1007/s10461-012-0344-5

Meehan, S. A., Leon, N., Naidoo, P., Jennings K., Burger R., \& Beyers N. (2015 ). Availability and acceptability of HIV counselling and testing services. A qualitative study comparing clients' experiences of accessing HIV testing at public sector primary health care facilities or non-governmental mobile services in Cape Town, South Africa. BMC Public Health., 15, 845. http://dx.doi.org/10.1186/s12889-015-2173-8

Metz, T. (2005). The Ethics of Routine HIV Testing: A Respect-Based Analysis. South African Journal on Human Rights, 21(3), 370-405.

Ministry of Health. (2011). Master Health Facility Liste-Health Kenya.Retrieved from http://www.ehealth.or.ke/facilities/

Musheke, M., Ntalasha, H., Gari, S., Mckenzie, O., Bond, V., \& Martin-Hilber, A. (2013). A systematic review of qualitative findings on factors enabling and deterring uptake of HIV testing in Sub-Saharan Africa. BMC Public Health., 13, 220. http://dx.doi.org/10.1186/1471-2458-13-220

National AIDS and STI Control Program. (2010). National Guidelines for HIV Testing and Counselling. Nairobi Kenya, Ministry of Health.

National AIDS and STI Control Program. (2013). Kenya AIDS Indicator Strategic Framework 2014/2015-2018/2019. Nairobi Kenya, Ministry of Health Retrieved from www.nacc.or.ke. 
National AIDS and STI Control Program. (2014). Kenya AIDS Indicator Survey 2012 Final Report. Nairobi Kenya, Ministry of Health Retrieved from www.nascop.or.ke.

Obermeyer, C. M., Bott, S., Bayer, R., Desclaux, A., \& Baggaley, R. (2013). MATCH Study Group. HIV testing and care in Burkina Faso, Kenya, Malawi and Uganda: ethics on the ground. BMC International Health and Human Rights, 13, 6. http://dx.doi.org/10.1186/1472-698X-13-6

Perez, F., Zvandaziva, C., Engelsmann, B., \& François, D. (2006). Acceptability of Routine HIV Testing ("Opt-Out") in Antenatal Services in Two Rural Districts of Zimbabwe. Journal of Acquired Immune Deficiency Syndromes, 41(4), 514-520.

Pizzo, E., Rayment, M., Thornton, A. C., \& Sullivanm A, K. (2012). Cost effectiveness of HIV testing in non-traditional settings- the HINTS study [Discussion paper 2012/05]. Retrieved from https://spiral.imperial.ac.uk/bitstream/10044/1/9787/1/Pizzo\%202012-05.pdf

SAS Institute Inc. (2012). Cary, NC. Patent No. :S.I. Inc.

Simpson, W. M., Johnstone, F. D., Boyd, F. M., Goldberg, D. J., Hart, G. J., \& Prescott, R. J. (1998). Uptake and acceptability of antenatal HIV testing: randomised controlled trial of different methods of offering the test. British Medical Journal, 316. http://dx.doi.org/10.1136/bmj.316.7127.262

Suthar, A. B., Ford, R., Bachanas, P. J., Wong, V. J., Rajan,J. S., \& Saltzman, A. K. (2013). Towards universal voluntary HIV testing and counselling: A systematic review and meta-analysis of community-based approaches. PloS Medicine, 10(8), e1001496. http://dx.doi.org/10.1371/journal.pmed.1001476

Thorntonm, C., Rayment, M., Elam, G., Atkins, M., Jones, R., \& Nardone, A. (2012). Exploring staff attitudes to routine HIV testing in non-traditional settings: a qualitative study in four healthcare facilities. Sexually Transmitted Infections, 88(8), 601-606. http://dx.doi.org/10.1136/sextrans-2012-050584

Treves-Kagan, S, Steward, W. T., Ntswane, H., Gilvydis, J., \& Gulati, H. (2016). Why increasing availability of ART is not enough: a rapid, community-based study on how HIV-related stigma impacts engagement to care in rural South Africa. BMC Public Health., 16(1), 87. http://dx.doi.org/10.1186/s12889-016-2753-2

Tshuma, N. T., Muloongo, K., Setswe, G., Chimoyi, L., Sarfo, B., \& Burger, D. (2015). Potential barriers to rapid testing for huma immunodeficiency virus amogn a commuter population in Johannesburg, South Africa. HIV/AIDS -Research and Palliative Care, 7, 11-19. http://dx.doi.org/10.2147/HIV.S71920

Walensky, R. P., Losina, E., Steger-Craven, K. A., \& Freedberg, K. A. (2002). Identifying Undiagnosed Human Immunodeficiency VirusThe Yield of Routine, Voluntary Inpatient Testing Archives of Internal Medicine, 162(8), 887-892. http://dx.doi.org/10.1001/archinte.162.8.887

White, D. A. E., Scribner, A. N., Schulden, J. D., Branson, B. M., \& Heffelfinger, J. D. (2009). Results of a Rapid HIV Screening and Diagnostic Testing Program in an Urban Emergency Department Annals of Emergency Medicine, 54(1), 56-64. http://dx.doi.org/10.1016/j.annermergmed.2008.09.027

World Health Organization. (2003). The right to know: New approaches to HIV testing and Counselling. Retrieved from http://www.who.int.hiv/pub/vct/en/Right_know_a4E.pdf

World Health Organization. (2012). Service Delivery approaches to HIV testing and Counselling: A strategic HTC policy framework. Retrieved from http://apps.who.int/iris/bitstream/10665/75206/1/9789241593877_eng_pdf

World Health Organization. (2013). HIV/AIDS: Statement on HIV testing and counselling: WHO, UNAIDS re-affirm opposition to mandatory HIV testing. Retrieved from http://www.who.int.hiv/events/2012/world_aids_day/hiv_testing_counselling/en/

World Health Organization. (2016). Global Health Observatory HIV/AIDS. Retrieved from http://www.who.int/gho/hiv/en/

Ziraba, A. K., Madise, N., Kimani, J. K., Oti, S., Mgomella, G., \& Matilu, M. (2011). Determinants of HIV testing and Counselling in Nairobi urban informal settlements. BMC Public Health., 11, 663. http://dx.doi.org/10.1186/1471-2458-11-663

\section{$(\mathrm{cc}) \mathrm{BY}$}

This work is licensed under a Creative Commons Attribution 3.0 License. 